\title{
Adsorption of basic dye onto palm kernel shell activated carbon: sorption equilibrium and kinetics studies
}

\begin{abstract}
Adsorbents prepared from palm kernel shell, an agricultural waste product, were used to remove a dye, Basic Blue 9, from an aqueous solution in batch mode at a constant temperature of $28^{\circ} \mathrm{C}$. The sorption kinetics and equilibrium of basic dye onto palm kernel shell activated carbon (PKSAC) were studied. The isotherm data were well described by the Redlich-Peterson isotherm model, with constants obtained from non-linear regression. The sorption kinetics are well described by the pseudo-second-order kinetic model. These studies suggested that PKSAC could be used as low-cost alternatives in wastewater treatment for dye removal. (C) 2005 Elsevier B.V. All rights reserved.
\end{abstract}

Keyword: Activated carbon; Adsorption; Basic Blue 9; Isotherm; Kinetics; Palm kernel shell 